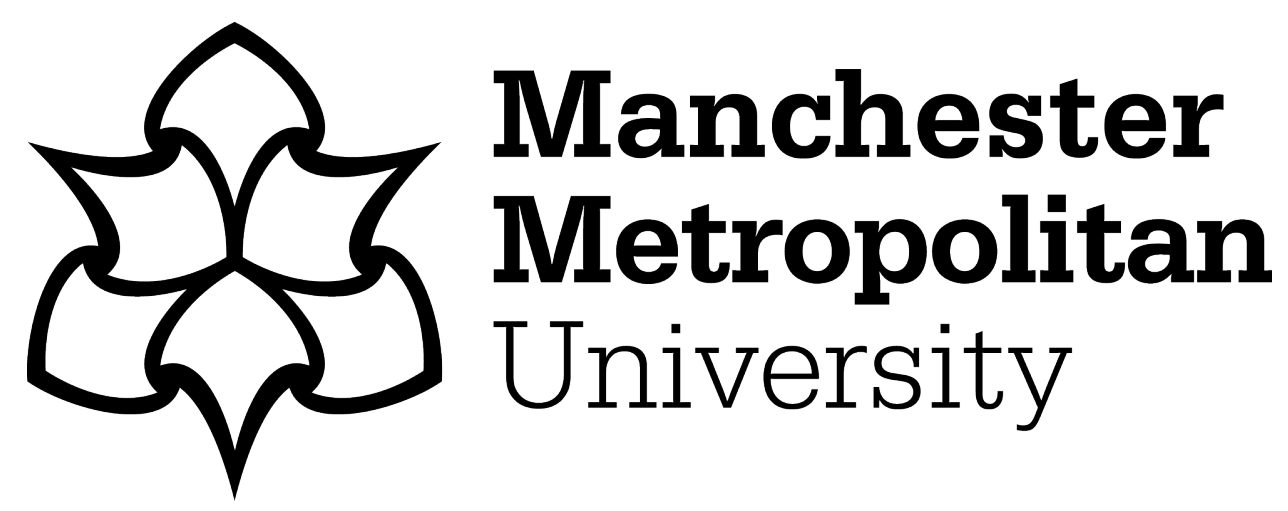

Edensor, T and Hughes, R (2021) Moving through a dappled world: the aesthetics of shade and shadow in place. Social and Cultural Geography, 22 (9). pp. 1307-1325. ISSN 1464-9365

Downloaded from: https://e-space.mmu.ac.uk/624748/

Version: Accepted Version

Publisher: Taylor \& Francis

DOI: https://doi.org/10.1080/14649365.2019.1705994

Please cite the published version 
Moving through a dappled world: The aesthetics of shade and shadow in place

Tim Edensor

Professor of Human Geography, Manchester Metropolitan University

Institute of Place Management, Manchester Metropolitan University Business

School, All Saints Campus, Oxford Road, Manchester M15 6BH, UK

t.edensor@mmu.ac.uk

Principal Research Fellow, Department of Geography

Melbourne University

Level 1/221 Bouverie St, Carlton VIC 3053, Melbourne, Australia

Rachel Hughes

Senior Research Fellow, Department of Geography

Melbourne University

Level 1/221 Bouverie St, Carlton VIC 3053, Melbourne, Australia

hughesr@unimelb.edu.au 


\title{
Moving through a dappled world: The aesthetics of shade and shadow in place
}

\begin{abstract}
In addressing geography's neglect of shade and shadow, this paper explores how the dynamic play of shadow and light constitutes an integral part of everyday affective and sensory attunement to place and guides pedestrian movement. First, we identify how particular shadows are shaped by distinctive kinds of solar radiance, material forms, human visual perception and cultural representations. We then consider the different cultural ways in which shade and shadow have been interpreted across space and time, and identify diverse shadowy effects in different geographical contexts. Thereafter, we focus on particular key elements of central Melbourne's shadow aesthetics, discuss how patterns of shade guide urban choreographies, and explore how architects have imaginatively manipulated shadow.
\end{abstract}

Key Words: Shade, shadow, light, place, aesthetics, design

\section{Seeing with light and shadow}

Shade and shadow have been strikingly neglected by geographers. Yet though we rarely pay heed to its multiplicities, we live in a dappled world in which variegated patterns of sunlight and shade play across space, enchanting landscape with colours, tones, textures and intensities that ceaselessly reconfigure apprehension and attention. This dynamic production of light and shade constitutes an integral part of everyday affective and sensory attunement to place. As we inhabit and move through dappled places, we are, as Ingold (2008) emphasises, immersed in the currents of a world in formation.

In this paper, we attempt to redress this absence by demonstrating how unique patterns of shade in Melbourne, Australia, produce distinctive spatial configurations and experiences of movement. First, we identify how particular shadows are shaped by the locational qualities of solar radiance, the material elements upon which light shines, the visual perception of humans and cultural interpretations and representations. We then consider the different cultural ways in which shade and shadow have been interpreted across space and time. After highlighting the diverse shadowy effects in different geographical contexts along with situated cultural responses, we focus on key elements of Melbourne's distinctive shadow aesthetics, looking at ornamentation and street furniture, vertical and horizontal expanses, and the shade produced by trees. Subsequently, we discuss how shade interacts with the city's built environment to shape urban choreographies, and finally, we explore how architects have contributed to Melbourne's aesthetic qualities by imaginatively manipulating shadow.

\section{Writing about light and shade}


In recent years, in addressing a rather startling lacuna, geographers have begun to consider how conditions of light and dark pervade spatial experience. A surge of explorations focus on how artificial illumination is conducive to the production of potent atmospheres and the sensory apprehension of everyday worlds (Edensor, 2012; Bille, 2019; Pink and Sumartojo, 2017). Others investigate the historical emergence of electric lighting and the contestations that continue to create 'new centres of power and new margins of exclusion' (Koslofsky, 2011, 280; also see Nye, 2015; Isenstadt, 2018; Jakle, 2001; Cubitt, 2013; Entwistle and Slater, 2019). More critical accounts examine the creative and socially progressive potentialities of light (Edensor, 2017b; Edensor and Sumartojo, 2018; Ebbensgaard, 2015). In addition, diverse studies of the effects and qualities of dark space have arisen (Dunn, 2016; Edensor, 2013; Dunnett, 2015; Shaw, 2014; Morris, 2011) as well as Peter Davidson's (2015) subtle exploration of twilight. However, academic accounts of the most prevalent light that we encounter during the day - sunlight - are curiously scanty (although see Edensor, 2017a). This paper seeks to supplement these accounts by investigating the qualities of the diurnal shadow that continuously emerges as an effect of the bright sunlight of Melbourne's summer, sidestepping the distinctively different properties of shadows cast by artificial light.

We argue here that we partially make sense of place by how we perceive with sunlight and its absence. A form of radiant energy, light is not perceived in itself but through how we visually discern the varying shapes, colours and intensities it produces. Light thus enters our eyes and enables us to distinguish a selective part of the electro-magnetic spectrum. The iris expands and contracts in controlling the amount of light admitted and the eye's convex lens focuses light to produce an inverted image on the retina. This image is sent via the optic nerve to the brain, which processes and interprets this information. Because of our distinctively human optical apparatus, we can continuously adjust to qualities of brilliance, colour, intensity, radiance, shade and gloom; however, our extremely particular visual abilities diverge from those of the many non-humans that discern objects that we cannot (Tyley, 2015).

We also perceive and conceive the world according to the quality of light that falls upon space. Different times of the day, seasons and prevailing weather conditions configure variable patterns and intensities of shade and light and mark the passage of time. Geographical location produces great global divergences in the diurnal and seasonal distribution of sunlight, as does the intensity of the sun's rays and the angle at which they radiate upon the earth, and the presence or absence of cloud and vaporous or dusty matter in the atmosphere that diffuses light. Yet whatever sunlight's specific qualities, we also perceive how it interacts with the distinctive material forms that reflect, deflect and absorb it, and the shapes and sizes of landforms, fixtures, buildings and living things that attract and block luminosity. Light is diffused by translucent clouds, reflected by water, absorbed by the pigment cells of plants and blocked by large trees. These manifold effects shape epistemological, affective and sensory experience of quotidian places and landscapes, which though largely habitually and unreflexively apprehended, anchor us, conditioning how we feel, practice and make sense of place. In this paper, we focus on how distinctive patterns and forms of shade and shadow shape the experience of one place: central Melbourne. The central part of the city possesses an extensive grid pattern, an increasingly high rise central business district, an array of $19^{\text {th }}$ century suburbs 
radiating outwards from this CBD, wide radial roads, numerous parks and green spaces, and distinctive architectural forms. From its foundation in 1837, Melbourne's built environment has been constructed and managed to accommodate the seasonal climatic variations of cold winters and luminous, hot summers. In Melbourne's summer months, sunlight burnishes the land with a particular intensity and clarity, producing lucidly distinguished objects and brilliant colours. It is the patterns, expositions and deep delineations of shadow produced by this powerful sun that we focus upon.

The discussion above reveals that light enables human vision by circulating between interior and exterior, blurring the division between the viewing subject and the landscape we perceive. This undergirds how we are therefore an integral part of the places we inhabit, never separate, distant onlookers. Despite this, landscapes and places are often reified by conventions of scientific classification, touristic gazing and aesthetic appreciation that instruct us how to look upon, assess, understand and characterise them. Such perspectives have perpetrated reductive notions of genii locus, the notion that each setting has its own identifiable, unchanging characteristics, though consistencies of luminosity and shade can certainly be identified. Although usually unaware, we ceaselessly respond to these shifting conditions by diverting our gaze towards particular objects, seeking shade or sun, or shielding our eyes, responses that disclose how a seething vitality inheres in all spaces and shapes our perceptions of them (Edensor 2017a). For the dynamic radiance and play of shadows reveal how landscapes are never pre-formed but are 'always in process... always in movement, always in making', vitally immanent and emergent (Bender 2001: 3; Benedicktsen and Lund, 2010), and we are part of this.

Seeing with the changing quantities, patterns and intensities of light and shadow involves different modes of looking within shifting fields of varying depth to apprehend the distinctive planes, angles and densities that constitute the variegated landscape (Wylie, 2006). An appreciation of the fluidity of the lightscape is articulated by Alphonso Lingis (1998), who identifies how changing levels of light, characterized by depth of field and brightness, continuously configure space, forming a fluid realm with which we continuously adjust (1998). Lingis uses the example of a red rose in a hospital room to focus on its chromatic relationality to the larger scene: the red of the rose intensifies the whites of the sheets and greens of the leaves, attracting our gaze. Gernot Böhme discusses how the shadow of a blue cup does not simply spread darkness across space but also spreads blueness. Böhme (1993: 121) terms the propensity for objects to tincture each other in this way 'ecstatic'. Similarly, an vibrant bright surface upon which the sun radiates is intensified by the contrastingly dark shadows that intersect and lie adjacent to it; and their darkness is correspondingly accentuated.

These incessantly unfolding levels of light, colour and shade to which we continuously become attuned provoke affective and emotional resonances, stimulate attention, remain unnoticed, or solicit movement towards or away from objects. Yet where dazzling light dramatically contrasts with deep shade, we may adopt more conscious mobile strategies to avoid discomfort or safely negotiate space. Moreover, shadows mark the passage of the day, month or year, for instance, with a shadowless midday perhaps soliciting desires to move inside while long evening 
shadows might stimulate anticipation of the coming evening. And autumnal shadows intimate the colder months that lie ahead.

Shadows are sometimes distinguished from shade, yet the capacity of shade to slowly mutate into distinct shadowy forms and vice versa across landscapes makes the distinction fluid. The infinitesimally fine gradations between the vaguely discerned pale shadow and filtered light across surfaces, and strongly demarcated deep shade make such divisions questionable. Accordingly, in this paper we refer to both interchangeably.

\section{Cultures of light}

Although light and shadow herald landscape's liveliness, we can only interpret our sensory apprehension of the distinctive light, colour and shadow of place through cultural values and conceptions (Bille, 2019). As Constance Classen emphasises, '(W)e not only think about our senses, we think through them' (1993: 9). Thus, distinctive cultures of looking ensure that seeing with light and shade does not provide unmediated access to reality; rather 'seeing involves movement, intention, memory, and imagination' (Macpherson, 1049: 2009). The ways in which we make sense of what we see with light and shadow veer from the cosmological to the moral, and from the aesthetic to the political, and vary enormously across time and space. As Veronica Strang insists, we formulate mythical, imaginative and symbolic concepts and categories that are aligned with our phenomenological experiences of space and place (2005), local understandings that are often substantiated and supplemented by representations in photography, painting, film and literature. For instance, Junichiro Tanizaki repudiates Western obsessions with illuminating space by focusing upon the aesthetic potency of the multiple tones of shadowy grey that wash across Japanese urban interiors and exterior settings. Tanizaki finds beauty 'in the patterns of shadows, the light and the darkness, that one thing against another creates' (2001: 2).

By contrast, deeply entrenched attitudes towards 'dark things', 'realms' and 'forces' reinforce Northern European associations of shadows with the pervasive gloom that preceded the modern age, in which superstition and religious beliefs were fostered in conditions where illumination was scanty and supplemented by a disorderly environment that made venturing out after sundown perilous (Edensor, 2017b). Mythological interpretations include ideas that shadows contain our repressed fears and inhibitions, are a kind of alter-ego, symbolise a parallel shadowy world, or herald a sense of foreboding (a shadow 'fell over' a situation, place or person). Malign creatures might lurk in the shadows. Yet shade has also been conceived as distinguishing the human from the supernatural or evil: European vampires cast no shadow and are afraid of shadows.

Following these negative conceptions, Michel Foucault establishes how a key ideal of modernist thought was to 'shed light on all things' in the pursuit of 'truth, purity, revelation and knowledge' by banishing 'the pall of gloom which prevents the full visibility of things, men and truths' (1980: 153). Stephen Kite (2017) argues that such Enlightenment obsessions were accompanied by moral imperatives amongst modernist architects and theorists to flood cities and building interiors with light (also see Otter, 2008). Yet as Anthony Vidler contends, this also produces a contradictory 
'fascination with those same shadowy areas' (1992: 169) as evidenced in ghost stories and Victorian Gothic fantasies with their sepulchral dungeons, grottoes and crypts.

By contrast, for John Ruskin and romantic poets such as William Wordsworth, shadowy shapes and the realms of caves, forests and groves signify the sublime. And Kite (2017: 5) also foregrounds cultural associations in which shadows foster 'spaces for refuge, devotion, awe, political and theatrical display, mystery, power, coolness, psychological fantasises and so on'. Similarly, Victor Stoichita (1997) tracks the numerous, diverse ways in which shadows and shade have been deployed in art, displaying shifting symbolic meanings throughout Western history. These contesting cultural values and conventions are beautifully captured by two expressionist paintings by Melbourne-based artist Charles Blackman from his 1953 'schoolgirls' series that feature the city's characteristically intense summer sunlight. The first shows a schoolgirl slowly walking over an expansive flat surface, head bowed. Beyond lie the featureless facades of a row of houses. The solitary girl is accompanied only by her own very striking shadow stretching in front of her. Here the space and the impassive shadow suggest loneliness, alienation and an oppressive sense of unease in a dangerous urban world. In complete contrast is the second painting, featuring an impish schoolgirl playfully manipulating the shape of her own shadow against a patchwork wall. Here, the shadow is far from sinister but signifies childish fun.
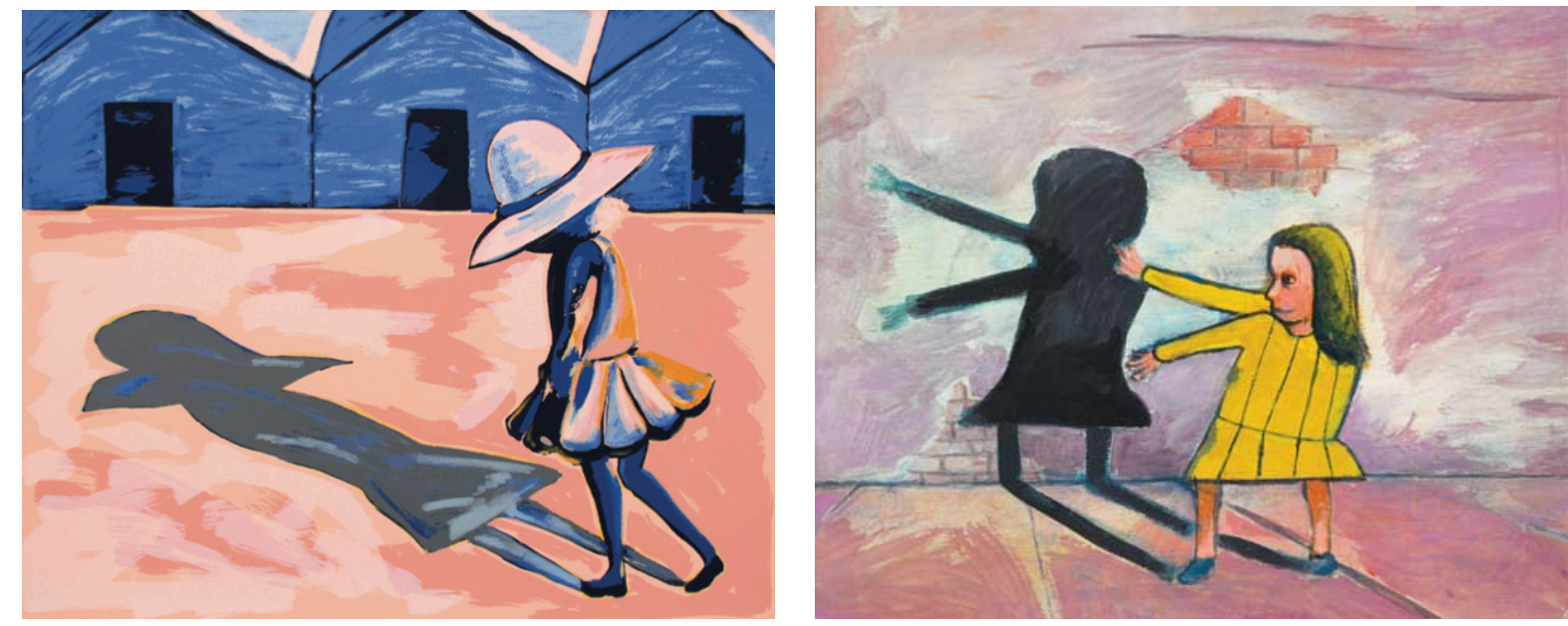

\section{Shadow, Place and Landscape}

In coming to cultivate a sense of place, a host of intensities or qualities are sensorially, emotionally and affectively apprehended, including temperature, humidity, density or expansiveness, colour, busyness, textures, smells and sounds. Such elements are all too perceptible but not always amenable to being pinned down, though writers and artists often try. Yet though often evanescent and difficult to articulate, experiencing such attributes is integral to a sense of belonging. It is in this context that we focus on the shadowy qualities of place.

In thinking about how shadow is an integral element of particular places and landscapes, we can identify a range of general consistencies. For instance, people inhabit particular conditions of luminosity and gloom according to divergent 
temporalities (Rantala et al, 2011). Towards the Arctic and Antarctic poles, in winter darkness pervades diurnal experience, limiting discrete shadows, while light floods the day in summer, producing changing shadows over many hours. In the Northern Hemisphere, these patterns are attributed to a broad Northernness, shaping interpretation and perception as well as social rhythms. By contrast, in the Tropics, the sun does not stray wildly throughout the year and seasonal variations of light and shadow are less marked. Christian Norberg-Schulz (1980) points to the pared down Middle Eastern landscapes that are harshly lit by cloudless skies, prompting denizens to seek shade in deep colonnades, covered bazaars, high walls and shaded courtyards. And according to Lavinia Greenlaw (2006), the temperate maritime climate of British landscapes generally take shape under cloudiness, mild shadows and weak sunlight, producing an atmosphere toned by subtle and everchanging patterns of light and shade. Pyrs Gruffudd (1991: 19) cites Steven Bone, the author of a 1946 book on weather, who proudly proclaims, 'it is this country with its changing skies and flying cloud shadows that has produced Wordsworth, Constable and Turner'. Henry Plummer submits that Scandinavian skies 'share a subdued light that imbues the entire region with mystery', a Nordic light typified by the 'low slant of the sun... long shadows and strikingly refracted colours' in winter months (2012: 6-7). Mikkel Bille (2019) pertinently discusses how such cultural constructions inform discursive formations of identity in these northerly European realms.

Melbourne's summer radiance and deep shadows are a variant of Australian luminosity, which is broadly characterized by a harsh sunlight that starkly contrasts with the light, shade and shadow that pervades European landscapes. Nevertheless, $19^{\text {th }}$ century European artists painted Australian rural scenes in colours that resonated with the cloudy landscapes that Greenlaw characterizes. Towards the end of the $19^{\text {th }}$ century, these styles were challenged by the Heidelberg school of painters who portrayed incandescent Victorian landscapes. Powerful Australian light subsequently came to symbolically differentiate the emergent nation from the British colonizing power (Miles, 2013) while retaining an aggressively white / settler claim, as represented in numerous Australian literary and visual representations, most famously in Dorothea Mackellar's iconic poem, I Love a Sunburnt Country and Max Dupain's renowned photograph, Sunbaker.

Interpretations of these distinctive patterns of shade and sun are evident in Aboriginal dot paintings that capture the vivacity of the landscape and the vibrant qualities of light (Young, 2011). The distinctive luminosity of Australian light is further distinguished by Barbara Bolt, who questions the Heideggerian enlightenment conception that light reveals truth and renders landscapes transparent to the onlooker. In the shadowless glare of the midday sun, she contends, nothing is revealed: 'too much light on the matter sheds no light on the matter' (2000: 204). The fuzzy, blinding glow of the sun thwarts Bolt's attempts to paint Kalgoorlie in Western Australia, a marginal desert landscape that - in the glare of the sun - is 'so fractured and messy that no form emerged' (ibid: 206). There is no clear distinction between foreground and background. Forced to avert her gaze from the blinding radiance, the ground becomes the dominant manifestation of light in the landscape. More prosaically, this powerful glare has other consequences: the historically popular enthusiasm for sunbathing has culminated in high rates of skin cancer. The 
capacities of the sun to dazzle vision, cause sweating and headaches, and generate thirst and uncomfortable overheating are now joined by more serious anxieties.

\section{The aesthetic configurations of shade and shadow in central Melbourne}

We now turn to consider the central focus of this paper, to investigate the distinctive shadowy forms and qualities of a particular place. We explore how the brilliant light of Melbourne, less intense than in Kalgoorie and other parts of Australia but nevertheless powerful, produces particular shadows and tones the experience of the central areas of the city, adding depth and texture. Strong summer sunlight and dry air create intense contrasts, sharp lines and clear-cut areas of shade. Critically, this luminosity casts shadows shaped by the distinctive material elements in the built environment that reflect, refract, absorb and block light in certain ways. While not all these conspicuous material forms are unique to the city, it is the ensemble of buildings, fixtures, vegetation and ornamentation that produce identifiable patterns of shadows across central Melbourne's landscape. The methodological approach for this paper was for each of us to walk on most summer week days for a period of three months compiling the regular shadowy effects that recurred along the city centre routes that we habitually walk along. By collecting photographs taken in a multitude of different locations during this everyday observation, we identified key consistencies and registered our sensory and affective responses to shade and shadowy forms. Several of these photographs feature here, illustrating our focus on the distinctive aesthetic configurations of the shadows of street fixtures and ornamentation, extensive vertical and horizontal expanses, and trees.

\section{Shadowy street fixtures and furniture}

As Thomas Reinhardt (2014) submits, we rarely notice shadows even when they are there. He further maintains that in discerning the objects upon which shadows fall, we generally focus upon the object not the shadow, for to concentrate on the shadow is to make the object obscure. Yet so prominent are the shadows of Melbourne in the fierce summer sun that they are utterly delineated from their surroundings, from the tone and hue of the surfaces and objects upon which they fall. On especially bright days, as the sun's angle lowers, certain street fixtures and utilities that face the light become hypervisible, standing out so that usually unnoticeable small details can be discerned. These intensely illuminated objects also become noticeable because of the deeply demarcated shadows that recede behind their luminous forms. In their conspicuousness, these shadows solicit an enhanced apprehension of the form and shape of the discrete railings, waste bins, lamps, chairs, tables and street signs to which they belong, many of which are designs chosen by city planners to bestow a particular place-based identity to public space. The objects to which the shadows are attached are newly revealed as shapely, almost sculptural, and thereby temporarily escape their typically utilitarian assignations (Figs 1a, 1b and 1c).

The most prominent effect of strong shadow is the enhancement of the distinctive, ornate and elaborate $19^{\text {th }}$ century cast iron lacework of Melbourne's inner city that adorns the gates, fences, awnings and verandas of numerous homes and shops (Fig $2 a)$. Facilitated by the wealth created by the mid- $19^{\text {th }}$ century Victorian goldfields, 
shadow amplifies awareness of these unique and diverse designs, accentuating its material affordances and shapely intricacies.

Besides transforming an intensified appreciation of the form and shape of objects, shadows can also take on wildly distorted shapes that diminish the presence of the object that they reflect. For instance, at a traffic light, the shadow of the fixture is monstrously elongated and a fire escape is much more impressive in shadowy than solid form (Fig 1b). These distorted forms are redolent of John Ruskin's (n.d.) consideration of the curious properties of the shadow, the 'strange shapes it gets into... and frets itself into all manner of fantastic schism, taking neither the shape of the thing that casts it, nor of that it is cast upon, but an extraordinary, stretched, flattened, fractured, ill-jointed anatomy of its own'. Thomas Reinhardt (2014: 205) also focuses on the ways in which shadows can appear to constitute separate things to the objects from which they extend. Indeed, he identifies the work of artists Larry Kagan and Kumi Yamashita, who have created extraordinarily shadows that seemingly bear no relation to the objects that produce them. Reinhardt remarks that these works promote 'a shift of agency' in that it is the 'shape of the shadows that determines the arrangement of metal or wood', contrasting with the usual subservience whereby shadows are 'mere appendages' to the 'real' objects. While a controlled beam of artificial light is essential to fix these artistically composed shadowy forms, the ever-shifting angle and position of the sunbeams that produces outdoor shadows means that they are more fluid, shape-shifting into diverse forms of varying length and complexity. Sometimes they suddenly announce themselves as fabulously distorted and dense entities; at other times they retreat into the background or become enveloped by larger expanses of extending shade.

Besides making ordinary objects appear extraordinary, the shadows cast on surfaces bring surrounding elements of the environment into play, making infrastructural elements and foliage more noticeable than usual (Fig 2b). Shadows cast by electric and telegraph wires embellish walls and pavements with crosscutting geometries, creating striking visual juxtapositions and transient patterns that possess a fleeting beauty. The gridded patterns made by mesh fencing similarly creates variegated arrangements of shadow across vertical and horizontal surfaces, 

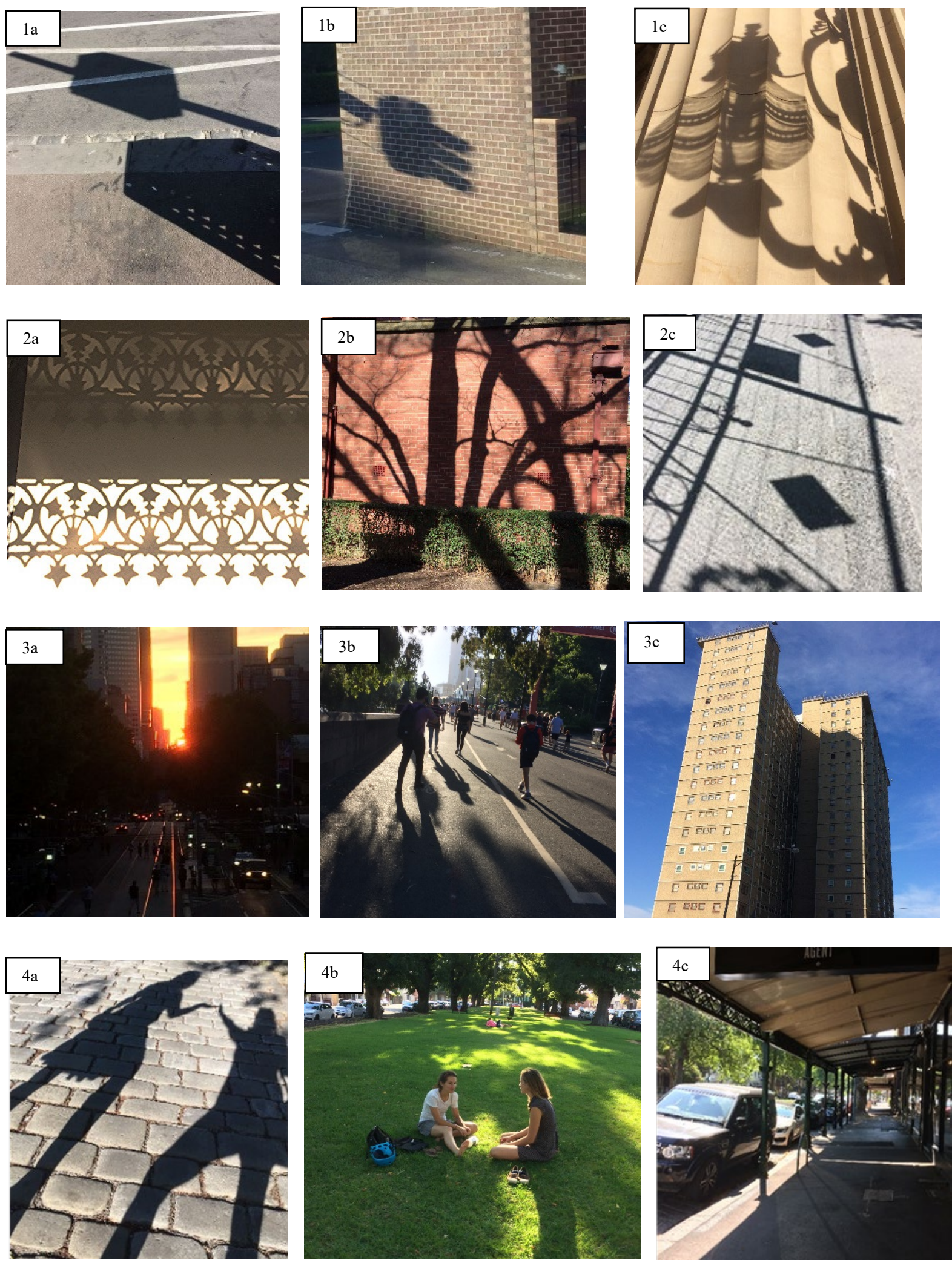

defamiliarizing the mundane textures of tarmac and paving (Fig 2c). Such shadowy patterns reveal the barriers that innocuously demarcate the boundaries of property 
and - in a time of widespread construction - guard construction sites against unwanted entry. Awareness of these temporary structures brings to attention the often-overlooked economic conditions that characterise periods of creative destruction. At present, such shadowy resonances proliferate across Melbourne, signifying the current project of city densification.

\section{Tall towers and wide roads}

Interspersed across Melbourne's inner suburbs are 47 huge public high-rise towers constructed by the Housing Commission of Victoria in the 1960s. Standing out against the low-rise suburban landscape, these giant blocks are transformed by the fluctuating play of light and shadow upon their rectilinear facades, and they cast thick, shifting swathes of shade across the surrounding neighbourhoods (Fig 3c). These changing shadowy patterns contrast with the more extensive shade produced by the increasingly dense clusters of large towers in areas of the city centre, part of a global trend towards vertical urbanism (Graham, 2016). Here, towers already built or in the process of construction block out access to direct sunlight despite 'setback' planning regulations. Here, deeply dark alleyways and service areas add to the sense of gloom despite the radiance available elsewhere in the city. Journalist Shane Green (2015) describes how a brief walk through this realm of massive, lofty structures generated by the current building boom has created a sense of defamiliarisation:

I walked a familiar path, but encountered the unfamiliar coldness generated by a new high rise that had blocked the sun. My city was fast becoming a Shadowlands, a bleak and uninviting place of concrete towers that changed not only the micro-climate, but the feel of the place, the very sense of what it is to be in Melbourne.

On the horizontal plane, prominent features of Melbourne's built environment are the flat, very straight roads that accommodate both trams and cars. In the summer months, the sun beats down on these wide expanses of asphalt and paving, creating a vast, glowing shimmer that reaches to the horizon. These linear plains of light create a medley of shadowy effect: objects stand out starkly, and where people are present, elongated shadowy figures extend out from their feet to animate the road surface, joining the long shadows cast by trees, walls and fixtures (Fig 3b). Nearer the city centre, the aforementioned large tower blocks along either side of these wide streets produce dark shade that intensifies the radiance of the street's luminous asphalt and create the impression of a broad-bottomed canyon. The combined effects of these horizontal and vertical features are spectacularly evident during 'Melbhenge', so called because of its parallels with the alignment of Stonehenge's monolithic stones during the summer solstice (Fig 3a). This annual occasion takes place in early February when the setting sun descends at an angle of 250 degrees west in brief alignment with the horizon of the Hoddle Grid, the rectilinear mesh of streets that form Melbourne's CBD designed by town planner Robert Hoddle in 1837. A throng of onlookers and photographers congregate on the steps of Victoria's Parliament Building to directly view the straight, undeviating stretch of Bourke Street, its asphalt radiant and tram tracks gleaming. 
Elsewhere, expanses of wasteland, car parks and the flat terrain of sports grounds are similarly adorned with striking shadows. On the blue stretch of the showcase tennis courts of Melbourne Park, home to the Australian Open during January, the steep banks of seating produce dramatic contrasts of light and shade as evening nears, creating difficult visual conditions for players. On the sixth day of the 2019 competition, champion Novak Djokovic's campaign was nearly derailed by severe light contrast in Rod Laver Arena. He audibly complained to his box: 'I can't see' (Fox Sports, 19/1/19).

\section{Shadows of Trees and Humans}

Ways of looking and seeing with light and shade can also inform the design of arboreal landscapes, as Böhme (1993) exemplifies in discussing how shadow is orchestrated in landscape gardening to 'tune' space by managing the light that filters through woodland canopies. Melbourne's inner suburbs are extremely well provided with many large and small green public spaces, avenues, cemeteries and large public parks that primarily derive from the $19^{\text {th }}$ century. Following fashions in British park design, these realms were well stocked with trees that flourished across Northern Europe - deciduous English oaks, plane trees and elms - as well as with thick indigenous evergreens such as Moreton Bay figs. Until recent extended drought periods, these species have been well suited to Melbourne's climate, and they continue to provide generous tracts of shade that are eagerly sought in times of bright light and high temperatures (Fig 4b). For instance, the path that runs along the north side of Carlton Gardens in the inner-city suburb of Carlton is deeply shaded by large elms. On hot days, the adjacent grassed areas become cool strips of conviviality, with people lounging, romancing, reading, phoning or exercising singly or in groups. These dense, extensive shady blotches of the city's central parks contrast with the streaky, striped shadowy patterns afforded by the indigenous eucalypts that are more populous towards the city's outskirts. In recognising their value in providing shade, as well as in absorbing pollution, storing carbon and ameliorating rising temperatures and the urban heat island effect, Melbourne City Council plans to extend the spread of trees as part of their world-leading Urban Forest programme (Phillips and Atchison, 2018).

A further key dimension of experiencing shade in brilliantly illumined Melbourne is that in continuously encountering our own shadows, we become attuned to our own presence in the landscape (Fig 4a). The ways in which the angle of the light stretches or condenses our own body shape can conjure up fantastical alternative beings, chiming with the ways in which shadow has been a focus for myths, supernatural powers and melodramatic cinema as discussed above. Nevertheless, it affirms that our bodies are an integral part of the urban landscape: we are not dispassionate entities that lack agency and simply evaluate; rather, we are part of the infinite elements that interact with the circulating vitality of light, air and matter. We block out the light and make a moving shadow on the earth.

\section{Shade and the production of choreographies}

Having considered the aesthetic patterns of shade and shadow fashioned by fixtures, ornamental designs, high towers, flat expanses, trees and peoples' bodies, 
we now consider how shady patterns shape our sensory inhabitation of Melbourne's built environment when summer sunlight is especially radiant. At these times, shade is an important resource, offering temporary respite from heat and dazzle, and consequently, it also shapes the experience of movement across space, influencing the performance of particular urban choreographies.

According to Henri Lefebvre, the walking body is enmeshed within an assemblage of instructions, spaces and architectures, and trained to perform required manoeuvres at a correct pace, style and rhythm. This exemplifies dressage, the breaking-in of the individual to (re)produce what he calls 'an automatism of repetitions'. After becoming unreflexively habituated to these disciplinary drills, the body thereafter performs regular, repetitive practices that rarely deviate from favoured modes of movement. 'In the street', Lefebvre writes, 'people can turn left and right, but their walk, the rhythm of their walking, their movements [gestes] do not change for all that' (2004: 40-1).

Though Lefebvre appositely identifies how rhythmic, habitual daily pedestrianism is formed, Hallam and Ingold contend that such accounts construe urbanites as passively re-enacting walking routines. On the contrary, they argue, walking is 'successional rather than processional' (2007: 12), and each discrete step is part of a fluid dance rather than a metronomic repetition. This emphasis on flow, on continuous shifting in response to changing contingencies, better captures the adaptive pedestrian practices performed on Melbourne's streets. Here, the vagaries of light and shade promote both practical improvisation and reiteration and, along with the specific affordances of place, guide the walking body along certain routes, disrupt and facilitate its progress, and cajole it into certain paces and rhythms. As elsewhere, individuals synchronise their movements with those of others, following regular paths and points of spatial and temporal intersection - at shops, bars, parks, cafes and pedestrian crossings - so that their daily tasks, pleasures and routines separate and cross with the trajectories of others. These co-coordinated collective choreographies of passage, stoppage and lingering produce what David Seamon (1980) calls 'place ballets', practices of 'dwelling-in-motion' (Sheller and Urry, 2006).

The summer sun in central Melbourne solicits distinctive place ballets as pedestrians seek to minimise their exposure to heat and radiance. Very often, the contrast between cool shaded environments and the thermal discomfort of areas bereft of shade is considerable, and entry into shade after walking in the sun can provide considerable respite as well as a distinctively different encounter with space. Accordingly, these collectively composed street choreographies are shaped by how pedestrians tend to walk in the available shade, altering their routes in accordance with the sun's strength. It must be emphasised that the provision of shade is unequally distributed across the city. The central areas through which we make the daily journeys discussed here are well provided with thick tree cover and canopies, and thus enable a greater capacity to shape routes according to plentifully available shade.

For instance, on hot, sunny mornings, pedestrians walking southwards in Melbourne typically keep to the left-hand side of the street, where adjacent buildings provide shade from the easterly sun. When such shaded routes are followed habitually, certain features become familiar markers of the journey while others on the opposite 
side of the street are rarely encountered, generating a distinctive lay knowledge of linear space. Alternatively, these choreographies may be reversed in the evening, or be improvisational, shaped according to the contingencies of the moment as part of a more variegated daily pedestrian schedule. Very often, only a few pedestrians brave the heat of the street's sunny side. For example, at the southern end of Lygon Street, also in Carlton, an area that hosts popular restaurants, bars, shops and boutiques, much of the pavement is installed with canopies that lure pedestrians, shoppers and diners into dense congregations when it is especially hot (Fig 4c). Yet even in areas where there is only a modicum of shade, such as at busy pedestrian crossing points, rather than hovering close to the kerb, pedestrians may pause in the shadows further back from the road to avoid even half a minute's exposure to the sun. Where tram stops necessitate waiting in the middle of a wide, sunny road, the very slender strip of shadow cast by a signpost may be sought out as a refuge. As we have mentioned, the copious shade dispensed by large European trees provides a resting and gathering site in the city's parks (see Whyte, 1980, for a comparison with New York's shade).

It bears repeating that these journeys, undertaken according to experience or contingency, are part of the practical inhabitation of place, but also configure how it is affectively and sensorially experienced. The sensations felt in spaces of heat and light may be interspersed with contrasting entry into darker realms, and degrees of fatigue may be dependent upon the extent to which bodies are exposed to sun. As the sun shifts position according to seasonal change, these choreographies and their attendant sensory experiences also alter. For instance, in early January, walking on Elgin Street towards Lygon Street, Tim typically sticks closely to the shady side of the street to avoid the intense light and heat. Yet this is reversed when walking to work along the same route in late March, for though the sun is often equally bright, a sharp chill caused by a cold wind may prompt him to move across to the sunny side of the street, into the warmth.

In Melbourne, shade and shadow enables or restricts tendencies to dine, browse or socialise on the street, and shapes the experience of the walking body, and its proclivities to sweat. It informs decisions about whether to apply sunscreen, wear particular clothes and how much time to spend walking. Any journey may be disaggregated into different stages within which particular actions can take place: to stop for a sip of water, linger in the shade, sit down, or put on and take off sunglasses and hats. Key junctures at which liquid is consumed or rest taken thicken this familiar encounter with place. Accordingly, moving through light and shadow cannot be disassociated from the aesthetic, affective and sensory experience of place - rather this contributes to how place is lived, practised and reproduced each day.

\section{Designing with Light and Shade}

The presence of canopies and trees highlights how the built environment has been partly designed to provide shade for inhabitants. In developing a more detailed exploration of how the qualities of sunlight might be exploited by architects and landscape designers, we now focus on how a concern with shaping shade has promoted a range of design innovations that contribute to a distinctive place-identity. The inventive manipulation of sunlight to produce extraordinary shadowy effects, we 
suggest, is contributing to the reinforcement of Melbourne's architectural distinctiveness.

In further considering the importance of canopies to Melbourne, many sturdy iron structures remain from the late $19^{\text {th }}$ and early $20^{\text {th }}$ centuries, some with delicate iron lacework that produce elaborate shadows, yet many more have been removed from the urban landscape. As Robyn Annear (2005) recounts, before Queen Elizabeth II visited in 1954, and as the city prepared to stage the 1956 Olympic Games, an obsession with 'civic neatness' and a desire to represent Melbourne as a modern city transcended colonial aesthetics impelled the destruction of many canopies. These awnings, especially installed on busy city streets, were designed to provide shelter from heavy rain and hot, blinding sun, and their removal both eliminated a civic amenity and diminished the distinctiveness of Melbourne's streets.
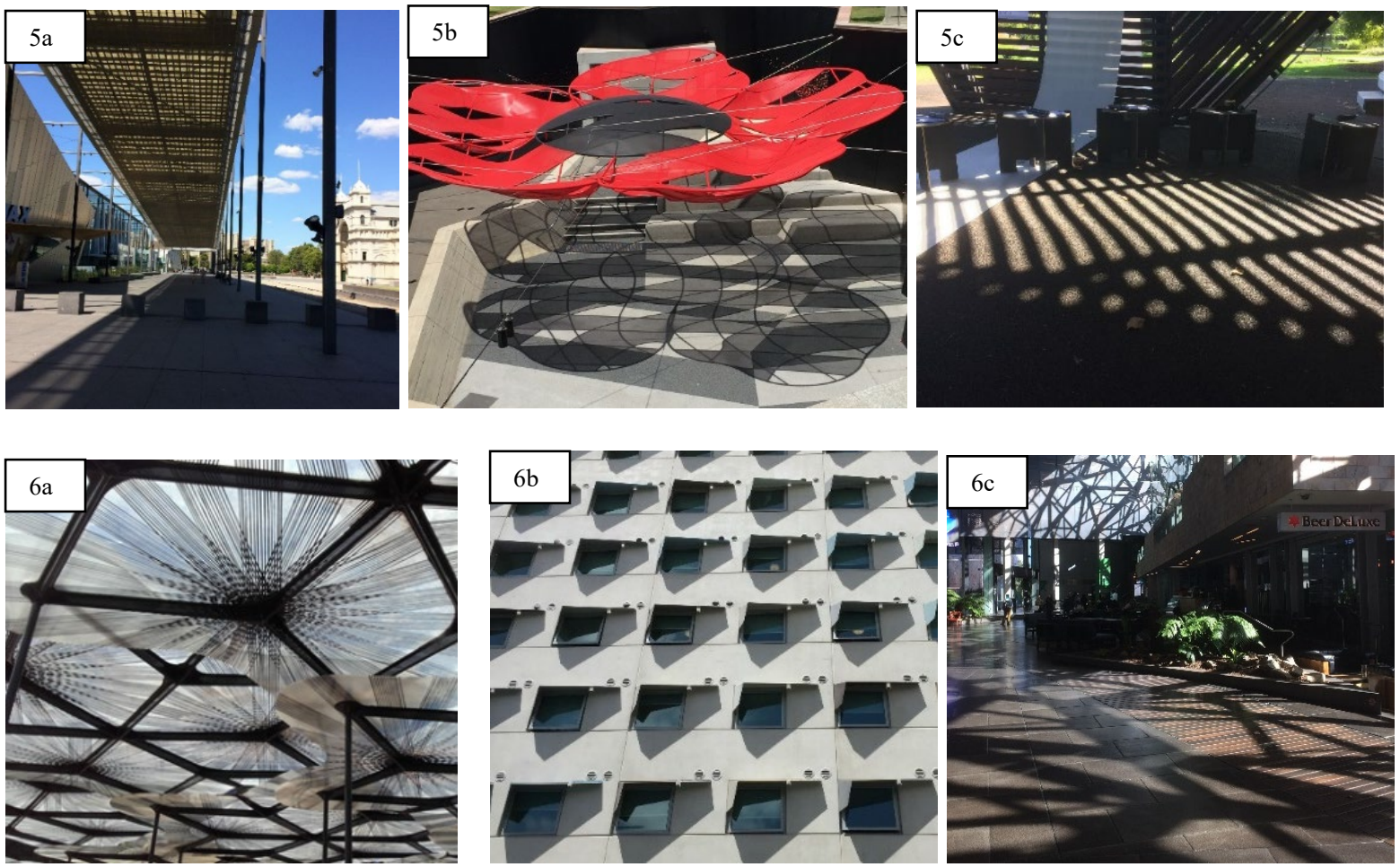

These removals have rendered bodies susceptible to both the heat and brilliance of the summer sun and to the frequent rain that descends on the city. Partly ameliorating this absence, in recent years, the existing canopies have been supplemented by new and varied designs. The Melbourne Museum in Carlton Gardens, completed in 2001, is approached theatrically, by walking in the shade provided by two high, very long sloping canopies, looming forms that provide thick blades of shadow in an otherwise sun-baked expanse of stone and concrete (Fig 5a). As part of the redevelopment of the Shrine of Remembrance site in 2014, a red canopy in the shape of a giant poppy covers one of the four newly-constructed pavilions (Fig $5 \mathrm{~b}$ ). Constituted by elaborate steel tubular tracery and a crosshatching of perforated aluminium sheets, complex, ever-changing patterns of shade play across the floor. Other canopy forms are distributed throughout the city in public and commercial spaces, including shade sails and much smaller fixed shade umbrellas. 
Perhaps Melbourne's most dramatic example of canopy design is the MPavilion, located in Queen Victoria Gardens (Fig 5c). Since 2014, a newly commissioned pavilion has been annually erected to host cultural events and public discussions for a four-month-long summer programme. Subsequently, each year's pavilion is relocated to another part of Melbourne. All designs deploy inventive contemporary construction techniques and materials, and work with the verdant surroundings and the changing light, but two designs particularly stand out for their sophisticated engagement with light and shade. The 2018-19 commission, designed by Spanish architect Carme Pinós, foregrounds the exquisite, shifting patterns of dappled light that filters through the latticed timber roof to transform the interior space of a folded, origami-like structure. And British architect Amanda Levete's 2015-16 Pavilion, subsequently relocated to Docklands Park, features a large canopy - composed of 43 three to five metre-wide translucent 'petals' supported by slender carbon fibre columns - that mimics light patterns across a forest floor (Fig 6a).

In considering designs beyond the canopy, we draw on Stephen Kite's (2017) account of the diverse shadow makers from different historical periods who have been influenced by a range of philosophical and cosmological conceptions about the relationship between light and shadow. These include the murky concrete Nordic church interiors created by Sigurd Lewerentz, the Baroque spaces devised by Hawksmoor and Vanbrugh, and the theatrical shadowy spaces designed by John Soane. Kite shows how many architects have focused on ecclesiastical interiors, creating dense shadows, supplemented by radiant glow or thin shafts of light, to foster a sense of divine mystery and primeval existence redolent of the cave and the forest. Similarly, Henry Plummer (2012) describes how Scandinavian architects, including Alvar Aalto, Sverre Fehn, Jørn Utzon and Arne Jacobsen, have often been preoccupied with capturing what they regard as the unique qualities of Nordic light. The production of myriad shadows has also been integral in the designs of Islamic architecture, exemplified by the extraordinary light effects of in the sensuous, elaborately carved screens, interlaced geometries, arches and domed ceilings spaces of the Alhambra, the Almoravid Andalusian palace fortress in Granada. Contemporary architects such as Aldo Rossi, Tado Andao and Peter Zumthor have sought to infuse the exterior spaces of their buildings with deeply inset windows and openings to produce thick rectilinear wedges of shadow. Perhaps the most influential modern architect in this regard is Louis Kahn (2003), who was preoccupied with the potentially limitless effects of what he referred to as a 'treasury of shadows', and focused on the production of shadows on facades and colonnades, and widely used shadow angles and small lateral apertures.

Equally detailed features are amply evident in the $19^{\text {th }}$ century and early $20^{\text {th }}$ century ecclesiastical and civic architecture of Melbourne, notably the gothic and neoclassical structures of the State Library, State Parliament, St Paul's Cathedral, Law Courts, Town Hall, and the $19^{\text {th }}$ century buildings at the western stretch of Collins Street. All these structures possess columns, recesses, ornamental facades and niches, create shifting light, shade and shadow according to diurnal and seasonal variation. Sharp-edged patterns of luminosity, shade and shadow are also evident in the city's many modernist structures where vertical and horizontal planes meet in angular conjunction. Such rectilinear designs afford a highly delineated shaping of shaded and bright surfaces across their facades, reinforcing apprehension of the geometrical qualities of these buildings. 
More recently, a greater contemporary focus on texture and pattern has encouraged architects to deploy shadow to emphasise distinctive geometrical patterning. Modest design features such as window shades, sills and pilasters are amplified as the sun strikes the vast facades that they adorn from different angles, shifting the configuration of pattern throughout the day and spectacularising surface geometries (Fig 6b). In the atrium of Melbourne's central Federation Square, ornamental arrangements of glass panels with steel framing creates an extraordinarily diverse environment of shadings and changing shadows (Fig 6c). Outside, Kite describes 'the fractal play of Australian sun and shadow in its tiled skin of zinc, glass and pink local sandstone' that he considers 'call to mind the dramatic patterns of shadow and light of the gorges and ravines of the Australian interior' (2017: 299-300). For Kite, the play of shadow in Federation Square does not connote melancholy or primordiality but directly signifies the blaze of a distinctively Australian sunlight and its geological refraction. These inventive approaches to designing with light and shadow imbue the centre of Melbourne with aesthetic effects that shift according to levels of light and shade, and allow bodies to move from solar brilliance to shady relief, thereby making the city more habitable and more experientially variable.

\section{Conclusion}

In this paper we have attempted to attune readers to a consideration of the characteristic qualities of shade and shadow in one place, Melbourne. We argue that geographies of shade are under-explored and the specific place-based effects of shadow and shade demand critical attention in a changing world for several reasons. Firstly, we have contended that while spaces and landscapes may be construed in essentialist ways through the identification of distinctive elements such as landforms, building styles, accents, foods and heritage sites, places also possess more evanescent, though still recognisable emotional, affective and sensory resonances: the cloudiness or clarity of the dominant sky, colours, surfaces, material textures and architectural shapes, the sense of openness or enclosure given by the height of buildings, the pace of pedestrian movement, the audible tones of street conversation, arboreal scents, and the distinctive play of light and shadows. Such characteristics are often barely noticed, but they nonetheless solicit an aesthetic, affective and sensory inhabitation, and we have sought to bring them to attention by tracking the evanescent, continuously changing aesthetic qualities of shadow in Melbourne. We have identified place-specific consistencies manifest in the distinctive patterns created by ornamentation and ordinary fixtures, expansive rectilinear horizontal and vertical elements in the built environment, and the dense foliage of trees.

Secondly, we have also focused on how the city's inhabitants live and move with these qualities, demonstrating how more and less-conscious movement through inner-Melbourne responds to sunlight, to heat and glare, and to welcome shade that gives thermal relief. Besides configuring distinctive place-ballets, we suggest that this foregrounds the necessity to provide ample shade in places that experience strong sunlight and heat, especially in a warming world in which conditions for movement may become more challenging. We have hinted how such provision is currently unevenly distributed, and is a civic amenity that should be more prevalent 
across central parts of the city and extend to encompass areas beyond the inner suburbs

Thirdly, we suggest that architecture, landscape architecture and design might more carefully respond to the specific qualities of shadow and light that pervade places. Understanding how such qualities are apprehended, appreciated, avoided or sought by those who live and move within a particular place is key to any such response. In a city such as Melbourne, there is vast potential for architectural designs and planning strategies to stage subtle and striking interactions between light and shadow. Indeed, as we have shown, architects are increasingly manipulating shadow in inventive ways to enhance the textures, depth and diversity of the built environment. We are certainly not alone in conceiving buildings, trees and other structures within the built environment as more than simply solid entities; as Tim Ingold suggests, they might be considered 'as much a thing of air, light, sound and mood (2016: 163). Architect Juhani Palaasma's (2014: 82) insistence that architectural space is not an inert setting but 'guides, choreographs and stimulates our actions, interests and moods' also echoes such an analysis. We thus urge greater consideration of light and shadow as integral qualities of space and place amongst designers, architects and place-managers.

\section{References}

Annear, R. (2014). A City Lost and Found: Whelan the Wrecker's Melbourne, Melbourne: Black Inc

Bender, B. (2001). Introduction, in B. Bender and M. Winer (eds) Contested Landscapes: Movement, Exile and Place, Oxford: Berg

Benedicktsen, K. and Lund, K. (2010). Introduction: starting a conversation with landscape in K .Benedicktsen and K. Lund (eds) Conversations with Landscape, Ashgate: Farnham.

Bille, M. (2019). Homely Atmospheres and Lighting Technologies in Denmark: Living with Light. Bloomsbury, London.

Böhme, G. (1993). Atmosphere as the fundamental concept of a new aesthetics. Thesis Eleven, 36(1), 113-126

Bolt, B. (2000). Shedding light for the matter, Hypatia, 15(2), 202-216

Classen, C. (1993). Worlds of Sense: Exploring the Senses in History and Across Cultures, London: Routledge

Cubitt, S. (2013). Electric light and electricity, Theory, Culture and Society, 30(7/8): 309-323

Davidson, P. (2015). The Last of the Light: About Twilight, London: Reaktion 
Dunn, N. (2016). Dark Matter: A Manifesto for the Nocturnal City. Arlesford, Hant: Zero Books.

Dunnett, O. (2015). Contested landscapes: the moral geographies of light pollution in Britain. Cultural Geographies, 22(4), 619-636.

Ebbensgaard, C. (2015). Illuminights: A Sensory Study of Illuminated Urban Environments in Copenhagen. Space and Culture, 18(2), 112-131

Edensor, T. (2012). Illuminated atmospheres: Anticipating and reproducing the flow of affective experience in Blackpool. Environment and Planning D: Society and Space, 30(6), 1103-1122

Edensor, T. (2013). Reconnecting with Darkness: experiencing landscapes and sites of gloom, Social and Cultural Geography, 14(4), 446-465.

Edensor, T. (2017a). Seeing with light and landscape: A walk around Stanton Moor, Landscape Research, 42(6), 616-633

Edensor, T. (2017b). From Light to Dark: Daylight, Illumination and Gloom, Minneapolis: Minnesota University Press

Edensor, T., and Sumartojo, S. (2018). Reconfiguring Familiar Worlds with Light Projection: The Gertrude Street Projection Festival, 2017. GeoHumanities, 4(1), 112-131

Entwistle, J. and Slater, D. (2019). Making space for "the social": connecting sociology and professional practices in urban lighting design, The British Journal of Sociology. Retrieved from :https://doi.org/10.1111/1468-4446.12657

Foucault, M. (1980). Power/Knowledge: Selected Interviews and Other Writings, 1972-1977, New York: Vintage.

Fox Sports (19/1/19). Australian Open 2019: live scores, results, Day 6 order of play for Saturday 19 January, updates, video https://www.foxsports.com.au/tennis/australian-open/australian-open-2019-livescores-results-day-6-order-of-play-for-saturday-19-january-updates-video/newsstory/8d2bcaa0c913339948514e50bfc712c2. (accessed 19/1/19)

Graham, S. (2016). Vertical: The City from Satellites to Bunkers. London: Verso.

Green, S. (15/10/15). Shadows over the CBD: have Melbournes skyscrapers reached a tipping point?, The Age

Greenlaw, L. (2006). Between the Ears: The Darkest Place in England, BBC Radio $3,(25 / 3 / 06)$

Gruffud, P. (1991). Reach for the sky: the air and English cultural nationalism, Landscape Research, 16(2): 19-24 
Hallam, E. and Ingold, T. (2007). Creativity and cultural improvisation: an introduction", in E. Hallam and T. Ingold (eds), Creativity and Cultural Improvisation London: Routledge.

Ingold, T. (2008). Bindings against boundaries: entanglements of life in an open world. Environment and planning A. 40(8), 1796-1810.

Ingold, T. (2016). Lighting up the atmosphere, in M. Bille and T. Sorensen (eds) Elements of Architecture: Assembling Archaeology, Atmosphere and the Performance of a Building Space, London: Routledge

Isenstadt, S. (2018). Electric Light: An Architectural History. Cambridge, MA: MIT Press.

Jakle, J. (2001). City Lights: Illuminating the American Night. Baltimore, MD: The John Hopkins University Press.

Kahn, L. (2003). Louis Kahn: Essential Texts, New York: W. W. Norton

Kite, S. (2017). Shadow-Makers: A Cultural History of Shadows in Architecture, London: Bloomsbury

Koslofsky, C. (2011). Evenings Empire: A History of Night in Early Modern Europe. Cambridge: Cambridge University Press

Lefebvre, H. (2004). Rhythmanalysis: Space, Time and Everyday Life. Trans. Stuart Elden \& Gerald Moore. London: Continuum.

Lingis, A. (1998). Foreign Bodies, Bloomington, In: Indiana University Press

MacPherson, H. (2009). The intercorporeal emergence of landscape: negotiating sight, blindness, and ideas of landscape in the British countryside, Environment and Planning A, 41, 1042-1054

Miles, M. (2013). Light, nation, and place in Australian photography, Photography and Culture, 6(3), 259-277

Morris, N. (2011). Night walking: darkness and sensory perception in a night-time landscape installation. Cultural Geographies, 18(3), 315-342.

Norberg-Schulz, C. (1980). Genius Loci: Towards a Phenomenology of Architecture (New York, Rizzoli)

Nye, D. (2015). The transformation of American urban space: early electric lighting, 1875-1915, in J. Meier, U. Hasenöhrl, K. Krause and M. Pottharst (eds) Urban Lighting, Light Pollution and Society, London: Routledge

Otter, C. (2008). The Victorian Eye: A Political History of Light and Vision in Britain, 1800-1910. Chicago: University of Chicago Press 
Palaasma, J. (2014). Space, place and atmosphere: emotion and peripheral experience in architectural experience, Lebenswelt: Aesthetics and Philosophy of Experience, 4, 230-245

Phillips, C. and Atchison, J. (2018). Seeing the trees for the (urban) forest: morethan-human geographies and urban greening, Australian Geographer, DOI: 10.1080/00049182.2018.1505285

Pink, S., and Sumartojo, S. (2018). The lit world: living with everyday urban automation. Social and Cultural Geography, 19(7), 1-20.

Plummer, H. (2012). Nordic Light: Modern Scandinavian Architecture, London: Thames and Hudson

Ruskin, J. Chapter V: Of Turnerian mystery: - secondly, wilful. in Modern Painters, Volume IV, Project Gutenburg:

https://www.gutenberg.org/files/31623/31623-h/31623-h.htm

Rantala, O., Valtonen, A. and Markuksela, V. (2011). Materializing tourist weather: ethnography on weather-wise wilderness guiding practices, Journal of Material Culture, 16(3), 285-300

Reinhardt, T. (2014). Fixing Shadows: Photography Beyond the Indexical. in Genge, G. and Stercken, A. eds. Art History and Fetishism Abroad: Global Shiftings in Media and Methods, New York: Columbia

Seamon, D. (1980). Body-subject, time-space routines, and place-ballets, in A. Buttimer and D. Seamon (ads) The Human Experience of Space and Place, London: Croom Helm.

Shaw, R. (2014). Controlling darkness: self, dark and the domestic night, Cultural Geographies 22(4), 585-600.

Sheller, M. and Urry, J. (2006). The new mobilities paradigm, Evironment and Planning A: Environment and Planning, 38, 207-226.

Stoichita, V.I. (1997). Short history of the shadow. Reaktion Books.

Strang, V. (2005) Common senses: water, sensory experience and the generation of meaning, Journal of Material Culture, 10(1), 92-120

Sumartojo, S., and Pink, S. (2017). Moving Through the Lit World: The Emergent Experience of Urban Paths. Space and Culture, 21(4), 358-374.

Tanizaki, J. (2001). In Praise of Shadows, London: Vintage Classics.

Tyley, J. (23/9/15). The science of vision: how do our eyes see, The Independent, https://www.independent.co.uk/life-style/health-and-families/features/the-science-ofvision-how-do-our-eyes-see-10513902.html (accessed 30/9/19) 
Vidler, A. (1992). The Architectural Uncanny: Essays in the Modern Unhomely Cambridge, MA: MIT Press

Whyte, W. (1980). The Social Life of Small Urban Spaces, New York: Project for Public Places

Wylie, J. (2006). Depths and folds: on landscape and the gazing subject, in Environment and Planning D: Society and Space, 24, 537-554

Young, D. (2011). Mutable things: colours as material practice in the northwest of South Australia, The Journal of the Royal Anthropological Institute, 17(2), 356-376 